\title{
Approaches regarding to the entrepreneurial practices of student in Romania
}

\author{
Maria Ciurea* \\ University of Petrosani, Department of Economics Sciences, University Street 20, Petrosani, \\ Romania
}

\begin{abstract}
Entrepreneurship is a skill that can be learned, so you do not have to be born with this skill to be a successful entrepreneur, but you can become a successful entrepreneur by learning and training certain skills. Entrepreneurial education contributes to the development of skills, knowledge and aptitudes necessary to achieve the objectives that stakeholders have set for themselves to become responsible and enterprising. These are relevant aspects for people with entrepreneurial education who are a real help in accessing a job more easily or more chances in setting up their own companies. The development of entrepreneurship among students generates a number of benefits both personally and in the community in which they live, such as: individual well-being, job creation, reduction of poverty and social inequities, economic growth. Therefore, this study aims to debate the topic of entrepreneurship and especially the identification of the main entrepreneurial practices that will be of real use in the development of entrepreneurial skills among students who want to opt for this field. The mentioned aspects will result in the increase of confidence, of the multiple perspectives and opportunities in the establishment and development of successful businesses of the graduates of higher education in Romania.
\end{abstract}

\section{Introduction}

Entrepreneurial activity is the driving force that supports the improvement of people's ability to achieve their goals through relationships between them, and the future of humanity depends on the ways of functioning of such an activity. Entrepreneurship is frequently associated with economic growth and development, improving living conditions, generating new jobs, technological progress, in other words the cause of prosperity in a society.

Stimulating entrepreneurial education is closely linked to creating inspiration for an entrepreneurial culture [1]. While this activity is traditionally seen as carried out in universities, there is now a strong recognition of the value of encouraging entrepreneurial expertise at all levels of education. For some initiatives, the goal is to promote the development of new businesses, but for many others, the goal is to encourage the development of more entrepreneurial attitudes and behaviours. At universities, the emphasis is now more on supporting students to start their own businesses. At the same time, entrepreneurship education helps to discover one's own potential, it can offer new materials

${ }^{*}$ Corresponding author: mariamacris2011@yahoo.com 
and studies for entrepreneurs in areas of major interest for those who already have a professional education in management and entrepreneurship [2]. In order to support productivity and growth in Europe, it is essential to invest in education and training. Europe needs creative and innovative entrepreneurs; it also needs a flexible and mobile workforce, with the necessary basic skills and competences. The European Commission recognizes entrepreneurship education as a tool that can help students to be more entrepreneurial and through which to develop a general set of skills, applicable in all aspects of life, not just to learn how to run a business $[3,4]$.

Entrepreneurial education should not be confused with business or economic studies, as its purpose is to promote creativity, innovation, risk-taking and self-employment. Therefore, innovative education helps students and entrepreneurs to become more creative and confident in any activity they undertake, generates changes in mentality throughout life, leading to the acquisition and consolidation of a rich entrepreneurial culture [5]. To this is added the financial education that aims to contribute to the formation of a financial culture, which will allow students, future entrepreneurs to more easily understand how the national economy works and the opportunities offered by entrepreneurship. Thus, the role of entrepreneurship in the contemporary economy is a well-defined one, being the one that develops new models, brings innovative solutions, assumes the risks associated with business development and always seeks the right and real formula for success. However, in entrepreneurship, as in any other field, there are a number of obstacles for those who want to start and develop a business in Romania, among which, in the first place is the mentality and fear of failure [6]. Therefore, entrepreneurship can be a solution to the problem of employment of graduates to the extent that entrepreneurship education programs are complemented by fiscal facilities for Start-Ups, successful models or mentoring programs for young entrepreneurs. At the same time, interactions with other entrepreneurs can be the most important learning resources, followed by direct learning from practice, books, studies, discussions with mentors and offline and online courses, will greatly contribute to the development of student entrepreneurial skills.

\section{Research methodology}

This study has a theoretical character and for its elaboration we conducted investigation of the scientific literature, using various search engines such as: entrepreneurial education, entrepreneurial practices, student entrepreneurial skills, entrepreneurial activity, successful business, specific to Romanian entrepreneurship. This information has been identified in various scientific articles in national and international journals, studies, papers published at various conferences and found on web portals and other international databases relevant to the field under investigation. In order to synthesize the information collected, more logical methods of scientific research were used, such as: analysis, synthesis, induction, deduction and analogy. Thus, their use resulted in their own approach to some relevant aspects of identifying student entrepreneurial practices in the phase of their acquisition, application, media coverage and stimulation, the knowledge of which makes a significant contribution to the development of students' skills in entrepreneurship.

\section{Results and discussions}

\subsection{Student entrepreneurial practices identified in the phase of acquiring skills}

Entrepreneurial education means more than training in how a company is run. It refers to how to develop entrepreneurial attitudes, skills and knowledge that should, in short, allow a 
student to turn ideas into action. Entrepreneurial skills require active methods to be determined to unleash creativity and the spirit of innovation. Entrepreneurial competence and skills can only be acquired or formed through practical and real learning experiences such as some of the activities to be presented below.

- Experience exchanges that can take place between teachers, students and economic agents, or young entrepreneurs. These exchanges of experience can take place in various forms, such as:

- regular meetings with businessmen from various fields of activity;

- visits to companies;

- workshops with students, University teachers and entrepreneurs who have developed a business;

- simulations and applications that facilitate the accumulation of knowledge in the field;

- other activities.

These experience exchanges will focus on acquiring skills and developing skills, transferring ideas, resources, information, contacts and recommendations, mentoring, professional business networking, providing a positive and structured environment in which to change recommendations quality from successful mentors or entrepreneurs. The exchanges of experience allow the participants (teachers/students) to acquire knowledge about the activity of entrepreneurs from different economic fields, and the economic agents/ young entrepreneurs to share their experience and professional practices with students and teachers. The purpose of such an action is to multiply the effects of experience exchange sessions, at institutional level, and to develop the preconditions for integrating the results into current practice.

- Entrepreneurial workshops aimed at supporting students and graduates to have access to activities that develop their entrepreneurial spirit. Within them there will be a constant communication with students about the opportunities they have, time will be allocated to present all the ideas in order to achieve the strategy and planning, to develop a viable business plan and providing feedback and guidance throughout this period. These entrepreneurial workshops will create an important and necessary bridge between academia and business, providing both optimal growth support for students and the opportunity for the private sector to better understand the training, needs and expectations of the current generation. The entire series of entrepreneurial workshops must bring in front of students, established entrepreneurs, creative people who have made a strong impression in the local, national and not only business environment, founders, managers, business specialists but also specialists in entrepreneurship related fields, where guests will present successful business development strategies and techniques and share their own stories designed to inspire, encourage and develop students' entrepreneurship [7]. Thus, students will have the opportunity to ask questions and have open discussions with the entrepreneurs present, while exercising certain skills, under the close supervision of a facilitator. An entrepreneurial workshop involves the active involvement of participants in the learning process that is built around the concept of non-formal education based on exercises and experiences.

- Entrepreneurial caravans aimed at informing students and making visits to universities to increase the number of students in their undergraduate programs. This activity involves the direct participation of the students they join and the support of the partner economic agents of the universities and the students will be supported to visit the universities. Also, students participating in complementary entrepreneurship courses will use the knowledge gained in the field of entrepreneurship and will perform specific actions for caravans, with the support of economic partners, to reach each of the localities where events will be attended by students. The purpose of these caravans is to support students in accessing tertiary education, to contribute significantly to awareness of the importance of participation in tertiary education and to increase the rate of access to this level of education, and in terms of 
entrepreneurship it will be achieved through the speech supported by the invited entrepreneurs about the experience gained in this field.

- Erasmus for Young Entrepreneurs is an effective tool for developing entrepreneurial skills among students taking place in 36 countries and is part of a project supported by the European Commission. It aims to increase the competitiveness of entrepreneurship and the development of SMEs in Europe. It is a cross-border exchange program between two categories of beneficiaries, namely new entrepreneurs (NEs), those who receive training and host entrepreneurs (HE), those who will provide training. The first category of young entrepreneurs is addressed to those who have started a business in the last 3 years or want to start one based on a business plan. Although the notion of young entrepreneurs seems limiting, it refers to business experience and not age. The beneficiary must be at the beginning of the business journey and have entrepreneurial knowledge because the purpose of the program is to help entrepreneurs enrich their business with new, creative ideas and develop new collaborations [8]. Through such a program, several benefits are obtained for new entrepreneurs, among which we can mention: building self-confidence and technical and management skills; creating opportunities for collaboration with other entrepreneurs and developing cooperation in cross-border business; building close relationships, business references; identification of business partners from abroad; gathering information on various cultural and organizational frameworks and how companies operate in another participating country; gathering information on the business environment from another participating country; development of language skills.

\subsection{Student entrepreneurial practices identified in the application phase of entrepreneurial skills}

A few years ago, competitive factors favoured the development of large companies that had a considerable ranking and professional management with which they could cope with largescale activities to penetrate and strengthen their position in certain markets. Currently, the changes in the information society are accelerating both internally and externally, and the newly established small companies, through the agility of entrepreneurs and their flexibility, are better able to cope with the current environment and competitive system [9]. In this context, the development of a new segment of companies, such as those to be presented below, is a natural process due to the many advantages offered by their organization, namely: flexibility in relations with business partners, quick management decisions and a number reduced by employees or collaborators.

- Start-Ups. Regarding the current market of Start-Ups in Romania, it is obvious that they are in a continuous development, which means that the approach to the initiative by local entrepreneurs is quite heterogeneous and there is no local culture and tradition in this sense. A trend of recent years is represented by the emergence of a segment of small entrepreneurs who have a corporate job give up it and choose to use their own "skills" in their own business, while making it a way to earn existence.

Another tendency is the development of Start-Ups in the IT field that were created due to the relationship of entrepreneurs with companies in this field, especially as employees. In general, start-ups are initiated by entrepreneurs up to the age of 30 , and one of the obstacles to the development of Start-Ups is financing, which is a particularly effective tool for European funds developed through the Operational Increasing Economic Competitiveness Program, Priority Axis 2 Competitiveness through research, technological development and innovation, Operation 2.3.1. Support for innovative start-ups and spin-offs. According to it, both Start-Ups defined as micro-enterprises or small enterprises with legal personality that have a maximum age of 3 years in the year of project submission and have a maximum of 20 employees and spin-offs that are companies eligible for financing, recently established or to 
be established on the basis of a recent result obtained from a research project of a public research organization or university [10]. The most important financing program that start-up entrepreneurs have at their disposal is still the Start-up Nation.

- Starting a business is often the best way to start a business and sometimes the only one possible. Opportunity-oriented businesses can sometimes only be started by starting a new business as opportunities can only be exploited in this way. If the business is targeting a new product or service, there is no other alternative. If the product or service is not new, but is in a growing market, there may be other companies on the market, but these are rarely for sale. The fact that no business is for sale in a particular market is a sign that there are still untapped opportunities in that market. Starting a business is much more difficult than buying an existing business or leasing, because everything has to start from the beginning. However, for many people, the process of turning a viable idea into a business is the true essence of entrepreneurship.

\subsection{Forms of organizing media activities and stimulating entrepreneurial practices}

Economic, social and educational realities highlight the need to grow and develop a new generation of entrepreneurs with characteristic skills such as responsibility, spontaneity, adaptability, flexibility, initiative and managerial spirit. These skills are essential for the profile of an entrepreneur, they generate specific skills in terms of identifying and implementing appropriate strategies for economic efficiency [11]. The development of such competencies cannot be achieved by itself, but it also needs other complementary aspects through which to be adequately improved and evolved entrepreneurial spirit of the relatives. In this context, there is a need for a diversification of activities through which to mediate and stimulate the various entrepreneurial practices, among which are those that are presented below.

- Student Entrepreneurship Societies (SAS) aim to create an enabling environment and a complementary framework for supporting and developing the entrepreneurial spirit of students in all educational cycles, including graduates from the last three years. Through its actions, SASs are a mechanism to support, develop and encourage entrepreneurship in the university environment, especially among students and graduates of higher education, in order to increase the competitiveness of Romanian universities. Within them, a series of activities are carried out, among which, we can mention [12]:

- elaboration of informative materials and guidance as support addressed to students in the elaboration and development of business plans, financing projects;

- facilitating the contact of students and graduates with entrepreneurs and mentors;

- organizing sessions of start-up projects, business ideas, etc., in order to select proposals to be submitted to the executive board for evaluation and feedback;

- organizing competitions to attract funding for the best projects;

- coordinating the activity of all business incubators, simulated enterprises and other entrepreneurial entities, within the higher education institution.

- organization of workshops and conferences with topics specific to entrepreneurship and business;

- advisory activities on specific topics for the elaboration of the business plan and the identification of the financing sources.

- Business incubators. Over time, it has been shown that new and small businesses usually fail due to lack of managerial skills or access to capital. In this context, the business incubator has become an attractive and widely accepted tool as a means to increase the chances of survival for new business projects and to support the development of an attractive business environment. From an operational point of view, the business incubator covers a wide range 
of processes that help reduce the failure rate of companies and accelerate the development of those that have the potential to become generators of jobs and well-being, and from a structural point of view, incubators include several key elements, namely an entrepreneurial and training environment, access to mentors and investors, books and market visibility. A business incubator collaborates with the community in which it operates to provide business assistance programs and entrepreneurs who place their businesses in such an incubator, as "consumers", act in an interdependent co-production relationship with the incubator [13].

In Romania the legal framework for the development of incubators was created, through which certain conditions for their creation were imposed, namely creating a minimum number of jobs and incubating a minimum number of companies for a general or sectorial incubator. The amount of time a company spends in a business incubator, allows support services to be provided, such as: office space, financial support, and consulting services across multiple stage.

- Business hubs \& accelerators. One of the current directions in terms of entrepreneurship development is given by business hubs or accelerators. They are functional in many of the systems with capitalist tradition and have appeared relatively recently in the Romanian economic space (in very dynamic market niches such as IT). For a company that has carried out activities and developed over a period of three years in an incubator, the next step is to participate in a business accelerator. Thus, if in an incubator the company had access to a workspace that included the related services necessary for a company at the beginning of the road, in an accelerator, there are mentoring and investment programs, workshops, specialized workshops [14].

For local companies that want to be included in an acceleration program, two ways are available, namely the application directly on the websites of the main accelerators in the world and the participation in various start-up events in Europe. During the three months of working in an accelerator, entrepreneurs can develop their business presentation skills, both in terms of planning and market potential, so as to convince potential investors of the efficiency of the investment. In our country there are several pre-acceleration programs with an educational component, such as: Innovation Labs and the annual MVP Academy program. In conclusion, while in incubators companies learn to start a business, the accelerators have the role of helping them in the transition to a stage of mature development in which to develop institutionally, to acquire value and a stable financial profile.

- Coworking spaces are large spaces where any entrepreneur has the opportunity to rent an office that is represented by an open space in which you get to work with other entrepreneurs or freelancers working on various new projects. It is very interesting that you can find partners for your business very easily, as well as you can find customers who need your services. In Romania, until now, coworking spaces have appeared in Brasov, ClujNapoca, Timisoara, Bucharest, Constanta, Iasi, Sibiu, Oradea and Saint George. They lay the foundations for a valuable community and support programs for entrepreneurs at the beginning of the road. This is also where Start-Ups that become success stories begin, which hire new people and obviously in this whole process they need a suitable working environment in which to grow, practically entrepreneurs work together, but each for their own business.

- Innovative clusters. Economic development and increasing global competitiveness are priorities for each country and any tool to accelerate them is important. Although economic practice has validated a model known in the literature as triple helix that brings together in a cluster representatives of the business environment, universities and research institutes and local or regional public authorities, for Romania it was necessary to adapt it in - a model such as "Four-leaf clover", the fourth actor being represented by catalyst organizations consulting companies specialized in the field of technology transfer and innovation, technology transfer centers. The effects of cluster development were determined by direct 
investment flows that concentrated where they found skilled labor, capital, experience, entrepreneurial traditions, suppliers, capital institutions and competitive research institutes, as well as adequate infrastructure $[15,16]$.

The promotion of entrepreneurial behaviour has allowed the definition of measures on the activity of clusters, which derive from research policies, innovation policies or those of business development and are implemented through various government programs. The best performing and most frequent clusters are innovative clusters with an impact on the level of competitiveness, considered the engine of economic development and innovation and determine a favourable framework for business development and collaboration between companies, research institutions, universities, suppliers, customers and competitors. Another category of clusters is that of regional clusters that have a particular impact on economic development in a given region.

\section{Conclusions}

Entrepreneurship development is a condition of successful business and having those qualities necessary for high level success will not be possible without paying special attention to training and education of entrepreneurship, capitalizing on certain opportunities, applying innovative practices and substantiating strategic objectives of management. The benefits of developing entrepreneurship are significant, both for those who start their own businesses and for society as a whole, which thus has the chance to prosper in an uncertain, everchanging world.

From the multitude of entrepreneurial practices identified during this paper, incubators are a tool for launching local entrepreneurial initiatives that can have a significant impact on a country's economy and can lead to the creation of a significant number of jobs. Also, the institutional factors involved in the performance of a cluster, the government and state institutions, universities, specialized research centers and last but not least companies will influence at all levels in a positive or negative way the business environment and its productivity, but can also have a important role in the economic development of the country.

In the extensive process of substantiating and launching entrepreneurial ideas by students, great attention must be paid to the importance of entrepreneurial innovation, emphasizing that innovation appears as a key factor in entrepreneurship today, due to fierce competition and the ever-changing economic environment. It is obvious that Romania has a long way to go in terms of investing in the development and promotion of entrepreneurial culture, as well as in stimulating the creation of the necessary framework for new businesses.

At the higher education level, entrepreneurship education has the greatest impact on entrepreneurship, given that most entrepreneurs are college graduates, and sound entrepreneurial and managerial knowledge can best develop at such a stage. Therefore, the academic environment must be the most favourable for the formation and development of entrepreneurial skills, stimulating creativity and innovation and that is why entrepreneurial training in universities is particularly important, as highlighted by some European studies, which show that companies set up by graduate students are the most innovative and ambitious in terms of turnover and number of jobs. In conclusion, this study is the starting point for a much more applied future research with clear and concrete data resulting from the investigations that will be carried out.

\section{References}

1. A. Kaklauskas, A. Banaitis, F.A.F. Ferreira, J.J.M. Ferreira, D. Amaratunga, N. Lepkova, I. Ubarte., N. Banaitienè, Sustainability, 10 (1), 119 (2018) 
2. M. Drăgușin, M.O. Sîrbu, R.M. Grosu, A.E. Iosif, Antreprenoriat. Teorie și practică (ASE, București, 2019)

3. OECD/EUROPEAN UNION (2019), Supporting Entrepreneurship and Innovation in Higher Education in Romania. Available on https://www.oecd.org/cfe/smes/HEInnovate-Romania.pdf

4. I.S. Rakos, M. Man, Journal of Accounting and Auditing: Research \& Practice, 1-22 (2016)

5. L. Dindire, M. Asandei, C. Gănescu, Theor Appl Econ 18 (9), 69-82 (2011)

6. D. Niță, Annals of the University of Petroşani, Economics, 19 (1), 85-98 (2019)

7. G. Domilescu, J of Edu Sciences, 1 (39), 81-89 (2019)

8. A. Macris, M. Macris, Annals of the University of Petroşani, Economics, 10 (4), 181-192 (2010)

9. E. Burduş, I. Cochină, L. Crăciun, A. Istocescu, Întreprinzătorul (Prouniversitaria, Bucureşti, 2010)

10. European Commission (2020), Specific Support. Start-ups, Scale-ups and Entrepreneurship in Romania.Available on https://rio.jrc.ec.europa.eu/sites/default/files/report/KI-AX-18-008-ENN.pdf

11. M. Macris, V. Ciurea, Internal Auditing \& Risk Management, 8 (3), 1-13 (2013).

12. C. Dura, C. Isac, D. Niţă, I. Drigă, M. Monea, Managementul afacerilor (Universitas, Petroşani, 2018)

13. C. Isac, Annals of the University of Petroşani, Economics, 17 (2), 123-130 (2017)

14. L. Pittaway, J. Gazzard, A. Shore, T.Williamson, Entrepreneurship \& Regional Development, 27 (3-4), 127-153 (2015)

15. M. Ciurea, Proceedings of the 1st International Scientific Conference Modern Management Trends and the Digital Economy: from Regional Development to Global Economic Growth MTDE 2019, 81, 638-642 (2019)

16. M.H. Morris, G. Shirokova, T. Tsukanova, European J International Management, 11 (1), 65-85 (2017) 